Onkologe 2016 $22: 815$

DOI 10.1007/s00761-016-0125-2

Online publiziert: 19. Oktober 2016

๑) Springer-Verlag Berlin Heidelberg 2016

CrossMark
J. Meran · J. Wallner

Abteilung f. Innere Medizin, Barmherzige Brüder Krankenhaus Wien, Wien, Österreich

\title{
Ablauf eines Ethikkonsils
}

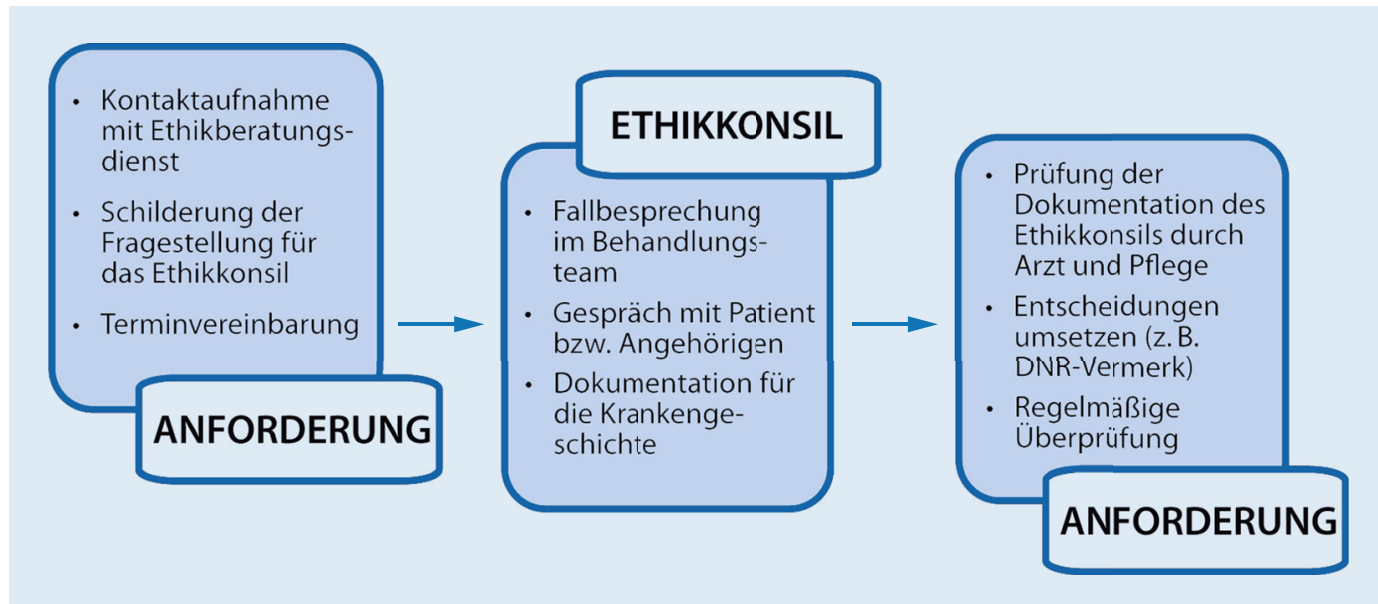

Abb. $1<$ Organisatorischer Ablauf eines Ethikkonsils. $D N R$, do not resuscitate", nicht reanimieren. (Mit freundl. Genehmigung Barmherzige Brüder Österreich)

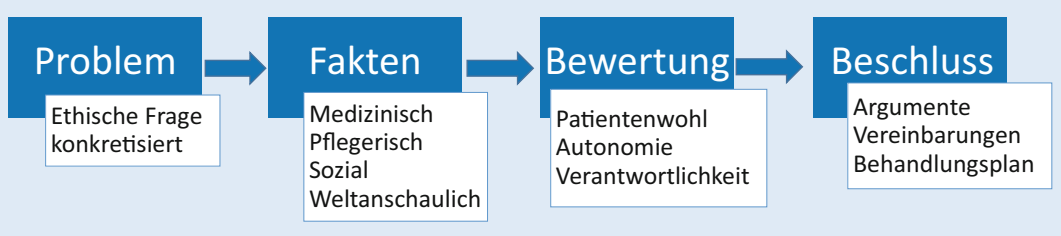

Abb. 2 ム Nimwegener Methode modifiziert nach: @ B. Gordijn: UMC St Raboud
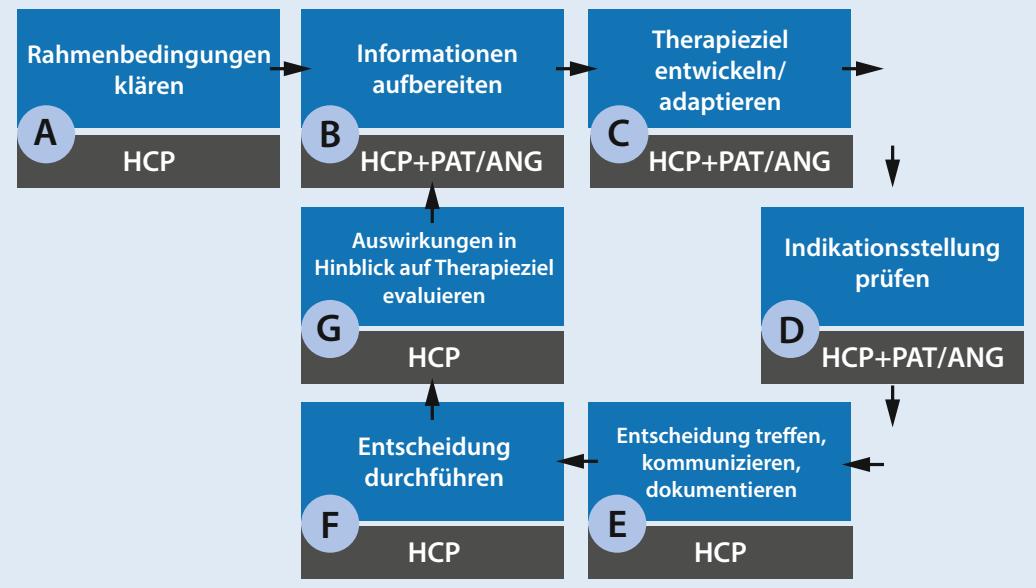

Abb. 3 ॥ Ablauf der Entscheidungsfindung. HCP Healthcare Professional, professionell im Gesundheitswesen Tätige, PAT Patient/Patientin, ANG Angehörige. (Mit freundl. Genehmigung Barmherzige Brüder Österreich)

\section{Korrespondenzadresse}

\section{Prim. Univ. Prof. Dr. J. Meran}

Abteilung f. Innere Medizin, Barmherzige Brüder Krankenhaus Wien

Johannes von Gott Platz 1, 1020 Wien, Österreich

johannes.meran@bbwien.at

Interessenkonflikt. J. Meran und J. Wallner geben an, dass kein Interessenkonflikt besteht. 